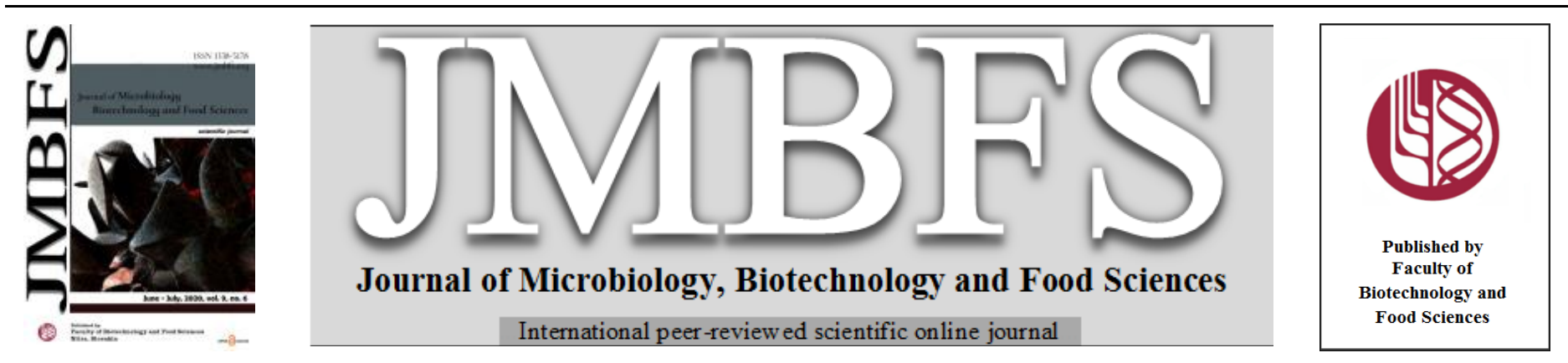

\title{
ASSESSMENT OF THE ALTERNARIA MYCOTOXIN TENUAZONIC ACID IN FRUIT JUICE SAMPLES
}

\author{
Vahid Safavizadeh $^{1,2}$, Ali Shayanfar ${ }^{3}$, Masoud Ansarin $^{4}$, Mahboob Nemati $^{5}$ \\ $\operatorname{Address}(e s):$ \\ ${ }^{1}$ Food and Drug Safety Research Center, Health Management and Safety Promotion Research Institute, Tabriz University of Medical Sciences, Tabriz, Iran. \\ ${ }^{2}$ Department of Pharmaceutical and Food Control, Faculty of Pharmacy, Tabriz University of Medical Sciences, Tabriz, Iran. \\ ${ }^{3}$ Pharmaceutical Analysis Research Center and Faculty of Pharmacy, Tabriz University of Medical Sciences, Tabriz, Iran. \\ ${ }^{4}$ Drug Applied Research Center, Tabriz University of Medical Sciences, Tabriz, Iran. \\ ${ }^{5}$ Halal Research Center of IRI, FDA, Tehran, Iran.
}

*Corresponding author: nematim@tbzmed.ac.ir

doi: 10.15414/jmbfs.2020.9.6.1162-1165

ARTICLE INFO

Received 1. 10. 2019

Revised 12. 2. 2020

Accepted 12. 2. 2020

Published 1. 6. 2020

Regular article

open $\odot$ access

\section{ABSTRACT}

Tenuazonic acid (TeA) is a secondary toxic metabolite that is produced by some Alternaria species. The aim of this study was to determine the presence of TeA in fruit juice samples. A total of 50 (40 Grape; 5 Apple; 5 Orange) fruit juice samples were collected from Tabriz, Iran local market and were analyzed for TeA contamination via HPLC-UV. Analyte extraction was done by acetonitrile/water/formic acid (84/16/1 v/v/v). Lower limit of quantitation and upper limit of quantification for the developed method were $10 \mu \mathrm{g} / \mathrm{L}$ and $4000 \mu \mathrm{g} / \mathrm{L}$ respectively. Recovery ranged was between 96 to $108 \%$. The results showed $42.5 \%$ of grape juice samples were contaminated with TeA and the average concentration of TeA was $139.2 \pm 115.5 \mu \mathrm{g} / \mathrm{L}$. However, it was not detected in apple and orange juice samples. This is the first study on the presence of TeA in Iranian food samples and showed that the necessity of more supervision on the production of grape juice.

Keywords: Mycotoxins; Alternaria; Fruit Juices; HPLC; Tenuazonic Acid; Iran

\section{INTRODUCTION}

Some microfungi produce toxic secondary metabolites called mycotoxins (Amirkhizi, Arefhosseini, Ansarin, \& Nemati, 2015; Cunha, Sá, \& Fernandes, 2018; Fernández-Cruz, Mansilla, \& Tadeo, 2010; Pizzutti et al., 2014; Walravens et al., 2014). Mycotoxins are one of the most important contamination factors in plants and cause the destruction of crops (da Motta $\boldsymbol{\&}$ Valente Soares, 2000). Some of the most important types of fungi that produce mycotoxins are Aspergillus spp, Penicillium spp, Fusarium spp and Alternaria spp (Prelle, Spadaro, Garibaldi, \& Gullino, 2013; Walravens et al., 2014). Alternaria fungi are pathogens and saprophytic species that have the ability to grow at low temperature (De Berardis et al., 2018; Myresiotis, Testempasis, Vryzas, Karaoglanidis, \& Papadopoulou-Mourkidou, 2015). This mycotoxin could be found in grains, fruits, vegetables and oilseeds (Asam, Liu, Konitzer, \& Rychlik, 2011; Broggi et al., 2013; De Berardis et al., 2018). Generally, a wet environment (water activity aw $=0.98$ ) is suitable for the growth of this fungus (Siegel, Merkel, Koch, \& Nehls, 2010; Siegel, Rasenko, Koch, \& Nehls, 2009) therefore prevention of growth of mycotoxigenic fungi is the most important way to control its presence in the foodstuff (Prendes et al., 2018). Having melanize walls in the spores of the Alternaria, makes it possible, to protect themselves from the ultraviolet (UV) radiation and desiccation (Panel on Contam in the Food Ch, 2011). Alternaria species can produce more than 70 secondary toxic metabolites but a few of them are structurally identified and called mycotoxin (Siciliano et al., 2018; Wei et al., 2017; Zhao, Shao, Yang, \& Li, 2014). Concerns about public health increased, when many of articles reported the presence of Alternaria mycotoxins in foodstuff (Tralamazza, Piacentini, Iwase, \& Rocha, 2018; Zwickel, Klaffke, Richards, \& Rychlik, 2016). The major Alternaria mycotoxins have three structural classes, tenuazonic acid (TeA) derived from tetramic acid, alternariol $(\mathrm{AOH})$ and alternariol monomethyl ether (AME) and altenuene (ALT) are the dibenzopyrone derivatives and also perylene derivatives the alter toxins (ATX-I, ATX-II,ATXIII ) (da Cruz Cabral, Terminiello, Pinto, Nielsen, \& Patriarca, 2016; Müller \& Korn, 2013; Patriarca, Azcarate, Terminiello, \& Pinto, 2007; Zwickel et al., 2016). Their acute toxicity is followed as ALT $>\mathrm{TeA}>\mathrm{AME}$ and AOH. However, the study in this field is not enough and this data needs more research (Panel on Contam in the Food Ch, 2011).
TeA (5S)-3-acetyl-5[(2S)-butan-2-yl]-4-hydroxy-1,5-dihydro-1H-pyrrol-2-one, (Fig. 1) is a toxic metabolite, which is produced by Alternaria spp., Phoma sorghina and Pyricularia oryzae (Asam et al., 2013; Chen \& Qiang, 2017; Liu, Ge, Peng, \& Pan, 2017; Oliveira et al., 2017)

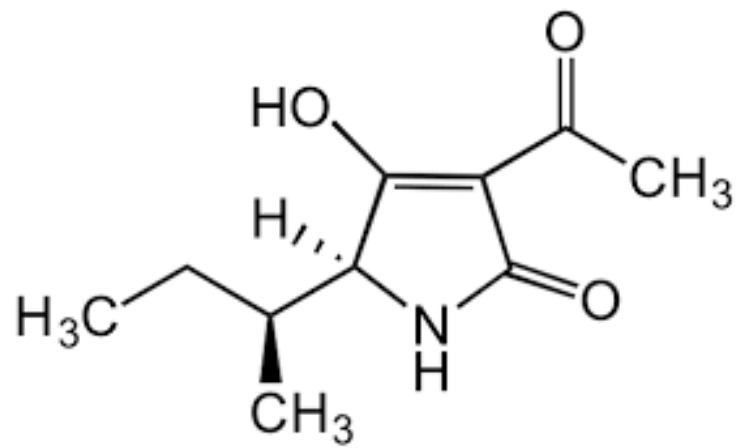

Figure 1 Chemical structures of TeA

TeA was found in agricultural products such as olives, cotton (seeds and bolls), sunflower seeds, peppers, tobacco seeds, sorghum kernels, rice, wheat, barley and oats as well as some fruits including apples, tomatoes, blueberries, lemons, oranges and wine and beer (Chen \& Qiang, 2017; De Berardis et al., 2018; Walravens et al., 2014). It is the cause of the human haematologic disorder called "onyalai" in central southern Africa (Fan, Cao, Liu, \& Wang, 2016). In addition, It has been suggested that in certain areas of China, the presence of Alternaria toxins in grains may cause oesophageal cancer (Panel on Contam in the Food Ch, 2011; Prelle et al., 2013) but due to the presence of other mycotoxins, so this conclusion needs more research (Panel on Contam in the Food Ch, 2011). The oral $\mathrm{LD}_{50}$ of TeA has been found to be 182 or $225 \mathrm{mg} / \mathrm{kg}$ body weight (BW) in male mice and $81 \mathrm{mg} / \mathrm{kg}$ body weight (BW) for female mice (Asam et al., 2013). Also, in Macaca fascicularis this limitation is 100-150 $\mathrm{mg} / \mathrm{kg}$ body weight (BW) (Liu et al., 2017). TeA inhibits protein biosynthesis and is biologically active, exerting antitumor, antiviral and antibiotic activities, together with cytotoxic and phytotoxic properties (Rychlik, Lepper, Weidner, \& Asam, 2016; Siegel et al., 2010). The European Food Safety Authority 
(EFSA) has set threshold of toxicological concern (TTC) value of $1.5 \mathrm{mg} \mathrm{TeA} / \mathrm{kg}$ BW per day for TeA (Panel on Contam in the Food Ch, 2011; Tralamazza et al., 2018). Many studies have already been done on mycotoxin in Iran and the detection of aflatoxin in foodstuff is one of the most commonly reported cases (A. Cheraghali et al., 2007; Dini et al., 2013; Fallah, Jafari, Fallah, \& Rahnama, 2009; Hashemi, 2016; Mazaheri, 2009; Nemati, Mehran, Hamed, \& Masoud, 2010; Rahimi, Bonyadian, Rafei, \& Kazemeini, 2010; Sani, Nikpooyan, \& Moshiri, 2010). In addition, the most studies about Fruit Juices have focused on the detection of Patulin (PAT)(A. M. Cheraghali et al., 2005; Khorasgani, Jalali, Hossieni, \& Gudarzi, 2010). A study in Argentina (2016) showed the presence of TeA in 57\% of wine grapes (Fontana, Prendes, Morata, \& Bottini, 2016). After reporting this research, it seems necessary to do a similar study in Iran to compare the presence of TeA in Iran with other countries. For the first time, in this study, TeA was analyzed in fruit juice samples of Iranian market by HPLC-UV because of fruit Juices is one of the most important beverage industry in the world (Asadpoor, Ansarin, \& Nemati, 2014).

\section{MATERIAL AND METHODS}

Chemicals

Acetonitrile and methanol, both HPLC gradient grade were supplied by DUKSAN (Gyeonggi-do, South Korea). Formic acid $(\geq 99 \%)$ and sodium phosphate monobasic $\left(\mathrm{NaH}_{2} \mathrm{PO}_{4}\right)$ were purchased from Merck (Darmstadt, Germany) and also phosphoric acid was obtained from Kimia Tehran acid co (Tehran, Iran). TeA was procured from Cayman Chemical Company (Ann Arbor, Michigan, United States) and the standard solution was prepared with methanol. Deionized water was prepared using a Mili- Q System(Tehran Absaz co, Iran).

\section{HPLC conditions}

The chromatographic system was a KNAUER HPLC instrument (Knauer, Berlin, Germany) consisting of a Detector S2500 Knauer equipped with a Biotech 2003 degasser (United State), K-1000 Knauer controller Quaternary pump and Rheodyne sample valve fitted with a $20 \mu \mathrm{l}$ loop (United State). The analytical column was SCIEX AAA C18 column $150 \times 4.6 \mathrm{~mm}, 5 \mu \mathrm{m}$ (Foster City, USA). The mobile phase was prepared freshly every day by a mixture of $\mathrm{MeOH}: 0.1 \mathrm{M}$ $\mathrm{NaH}_{2} \mathrm{PO}_{4}(2: 1 \mathrm{v} / \mathrm{v})$, adjusted to $\mathrm{pH} 3.2$ with phosphoric acid. The eluent flow rate was $1.5 \mathrm{ml} / \mathrm{min}$. The wavelength for recording chromatograms was $279 \mathrm{~nm}$ (Fontana et al., 2016).

\section{Samples}

A total of 50 homogenized juice samples (40 Grape; 5 Apple; 5 Orange) that made by Iranian and non-Iranian (Thailand, Belgium, South Korea) companies also homemade samples were analyzed. Samples were purchased in March-April 2018 and were randomly selected to quantification of TeA from retail stores.

\section{Sample preparation}

Sample preparation was preformed based on the reported method by Lopez and coworkers (38). The samples were shaken for homogeneity. Then, $2.5 \mathrm{~mL}$ of juice transferred to a $15 \mathrm{~mL}$ centrifuge tube and was mixed with $10 \mathrm{~mL}$ of acetonitrile/water/formic acid $(84 / 16 / 1 \mathrm{~V} / \mathrm{V} / \mathrm{V})$. The mixture was manually shaken for $5 \mathrm{~min}$. After centrifugation at $4000 \mathrm{rpm}$ for $5 \mathrm{~min}$, an aliquot of 0.5 $\mathrm{mL}$ of the supernatant was taken and filtered. Subsequently, $20 \mu \mathrm{L}$ of the solution was injected directly into the HPLC-UV system.

\section{Method validation parameters}

The HPLC-UV method for the determination of TeA in juices was validated for linearity, accuracy, precision. Calibration curve was prepared by spiking six concentrations $(10,50,125,250,500,1000 \mu \mathrm{g} / \mathrm{L})$ of TeA in a blank grape juice. The linearity was calculated using these six concentrations in triplicate also linearity requirements were fulfilled when the correlation coefficient was greater than 0.99. The calibration range included concentrations from the lower limit of quantification (LLOQ) to the upper limit of quantification (ULOQ). The LLOQ is defined as the lowest concentration of TeA can be determined with acceptable precision and accuracy as well as the highest amount of TeA that can be quantitatively determined with precision and accuracy is ULOQ (Ershadi \& Shayanfar, 2018; Kollipara, Bende, Agarwal, Varshney, \& Paliwal, 2011). Recovery and precision were evaluated over three consecutive days at three nominal TeA concentrations $(80,200$ and $400 \mu \mathrm{g} / \mathrm{L})$ by spiking an uncontaminated matrix.

\section{RESULTS AND DISCUSSION}

\section{Method validation}

For the developed analysis methods, coefficients of determination $\left(\mathrm{R}^{2}\right)$ above 0.99 show an acceptable linear relationship between concentration and response. In this research, $\mathrm{R}^{2}$ is obtained 0.999 . The sensitivity parameters, LLOQ and ULOQ were $10 \mu \mathrm{g} / \mathrm{L}$ and $1000 \mu \mathrm{g} / \mathrm{L}$ respectively. The validity of method was checked by three different concentrations of TeA in fruit sample. Details of the method validation for the developed analysis method for quantification of TeA in fruit samples have been listed in Table 1. The relative standard deviation (RSD) was from 1.5 to $2.8 \%$ for inter-day $(\mathrm{n}=3)$ and 2.9 to $6.6 \%$ for intra-days $(\mathrm{n}=3$, three days) analysis. The recovery of the developed method for quantification of TeA was between 96 to $108 \%$. The acceptable range for RSD is $\leq 20 \%$ and accuracy is $70 \%-120 \%$ (Fontana et al., 2016).

Table 1 Recovery and precision (as RSD) of the developed analysis method for quantification of TeA

\begin{tabular}{lllll}
\hline $\begin{array}{l}\text { TeA spiked } \\
\left(\boldsymbol{\mu g .} \mathbf{L}^{-\mathbf{1}}\right)\end{array}$ & $\begin{array}{l}\text { TeA found } \\
\left(\boldsymbol{\mu g .} \mathbf{L}^{-\mathbf{1}}\right)\end{array}$ & Recovery $(\%)$ & $\begin{array}{l}\text { RSD\% } \\
\text { Inter-day }\end{array}$ & $\begin{array}{l}\text { RSD\% } \\
\text { Intra-day }\end{array}$ \\
\hline 80 & 76.8 & $96 \%$ & 2.8 & 6.6 \\
\hline 200 & 202 & $101 \%$ & 1.8 & 5.1 \\
\hline 400 & 432 & $108 \%$ & 1.5 & 2.9 \\
\hline
\end{tabular}

\section{Comparison with HPLC-MS}

HPLC-UV and HPLC-MS are commonly used systems for TeA analysis. Each of these systems has advantages and disadvantages. However, HPLC-MS has more ability than HPLC-UV for detecting analytes but HPLC-UV was able to detect TeA sufficiently and had shown good efficiency. The reason for choosing HPLCUV in this study is its low cost and high availability. A few studies have been conducted on the presence of tenuazonic in foodstuffs throughout the world. More studies should be done especially in developing and least developed countries. In this study, we have tried to use methods that allow researchers around the world to analyze TeA in fruit juices by low cost and fast.

Survey of grape juice samples from the Iranian market

The above validated method was finally evaluated on the real fruit juice samples. Fig. 2 shows the HPLC analysis of TeA in fruit juice samples including a standard, spiked sample and a positive grape juice sample.
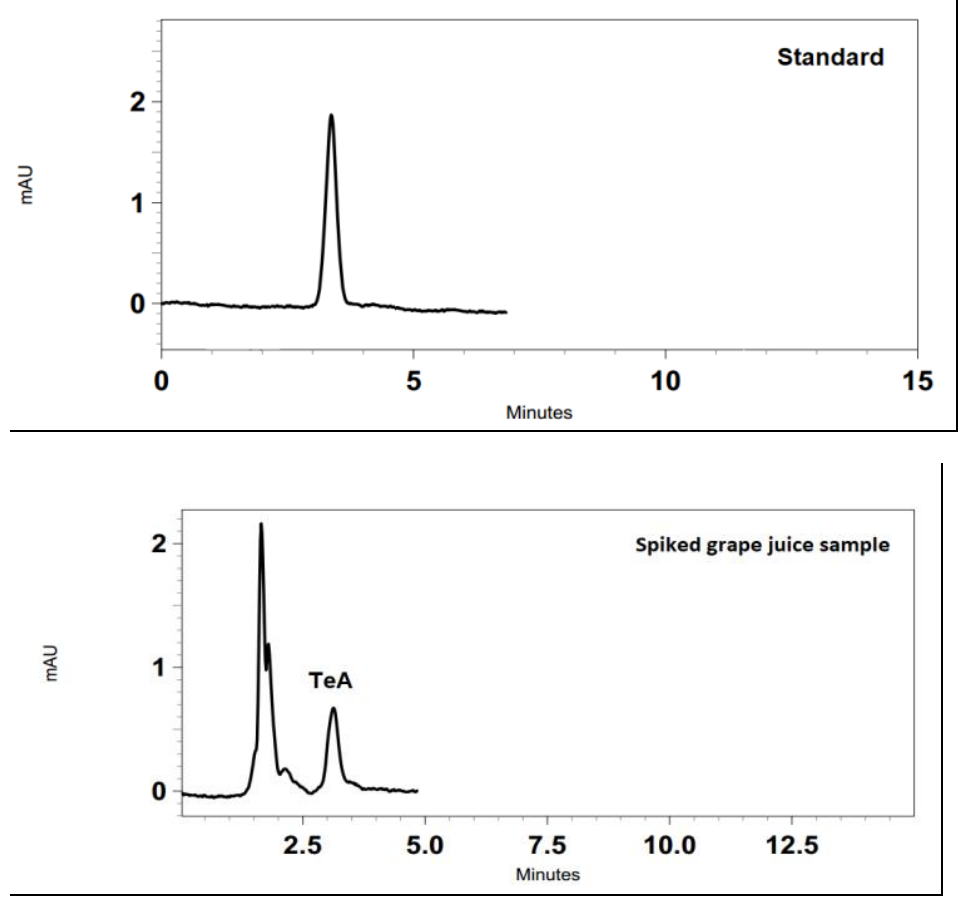


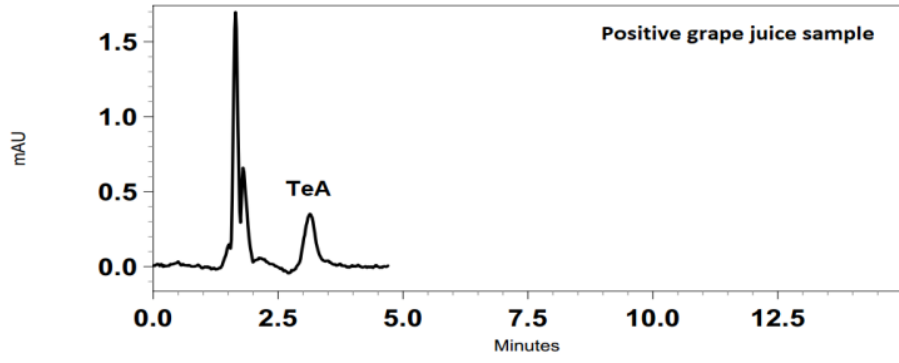

Figure 2 Chromatogram of (a) TeA in aqeous solution, (b) Fruit samples spiked with $\mathrm{TeA}(\mathrm{c})$ and a real fruit samples contaminated with $\mathrm{TeA}$ (positive sample)

The results of TeA concentration in positive samples were reported in Table 2. TeA was detected in 14 grape juice samples, respectively. In this study, samples from 4 countries were used and the concentration range from 212 to $702 \mu \mathrm{g} / \mathrm{L}$ was reported. As a result, TeA was present in over $32.5 \%$ of the grape juice samples. On the other hand one sample of grape juice, which expired 9 months ago was tested and the highest amount of TeA was observed in it. The maximum and minimum TeA concentrations was $212 \_702 \mu \mathrm{g} / \mathrm{L}$, respectively. However, $\mathrm{TeA}$ was not found in orange juice and apple juice samples.

\section{Comparison with results of other studies}

There are not many studies about the presence of TeA acid in foodstuff. In Table 3 , the most relevant reported studies for TeA level in other research studies have been compared. In a study in Italy (Prelle et al., 2013), TeA was detected in apple juice. Ten apple juice samples were analyzed and TeA was presented in two samples, but it was not found in Beers, Tomato products, Olive and Dried basil samples. In another study in Argentina (Fontana et al., 2016) on wine grapes, the presence of $\mathrm{TeA}$ in $57 \%$ of the samples was showed and the maximum contamination level of samples was $595 \mu \mathrm{g} / \mathrm{g}$. A survey in the Netherlands (López et al., 2016) showed that all Dried figs, sunflower seeds and mato sauces were contaminated with TeA, and also in three samples of wine hd one olive sample, TeA was detected. There was no TeA in the fresh citrus or pple juice samples.

able 2 Occurrence of TeA in real grape Juice samples (TeA was detected in $2.5 \%$ of grape juice samples). Average concentrations $\left(\mu \mathrm{g} \mathrm{L}^{-1}\right)$ with their andard deviations, $\mathrm{n}=3$ replicates

\begin{tabular}{ll}
\hline Sample code & Level found \\
\hline 1 & $234 \pm 7$ \\
\hline 2 & $353 \pm 3$ \\
\hline 3 & $597 \pm 2$ \\
\hline 4 & $375 \pm 4$ \\
\hline 5 & $608 \pm 6$ \\
\hline 6 & $702 \pm 11$ \\
\hline 8 & $334 \pm 6$ \\
\hline 9 & $358 \pm 3$ \\
\hline 10 & $393 \pm 3$ \\
\hline 11 & $289 \pm 3$ \\
\hline 12 & $428 \pm 2$ \\
\hline 13 & $212 \pm 4$ \\
\hline
\end{tabular}

An article from Germany about the occurrence of TeA in beers (Siegel et al., 2010) has been published that showed in 38 cases of 43 samples, TeA was detected and the highest average of contamination TeA was in bock beer Another study from Germany (Zwickel et al., 2016) presented that all of red wines and $72 \%$ of white wines were contaminated with TeA and $62 \%$ of all juice samples containing TeA. The best result from the assessment of TeA was a Canadian survey (Abramson, Delaquis, \& Smith, 2007), which TeA was not found in any sample of ice-wine. This result may be due to the limit of detection of $70 \mu \mathrm{g} / \mathrm{L}$. The results of a Chinese article (Fan et al., 2016), indicated that TeA had been found in 6 samples of apple juice and one case of walnut wine. According to these results, TeA can occur in a wide range of foodstuffs at various levels.

Table 3 Comparison of TeA presence in various samples with other studies

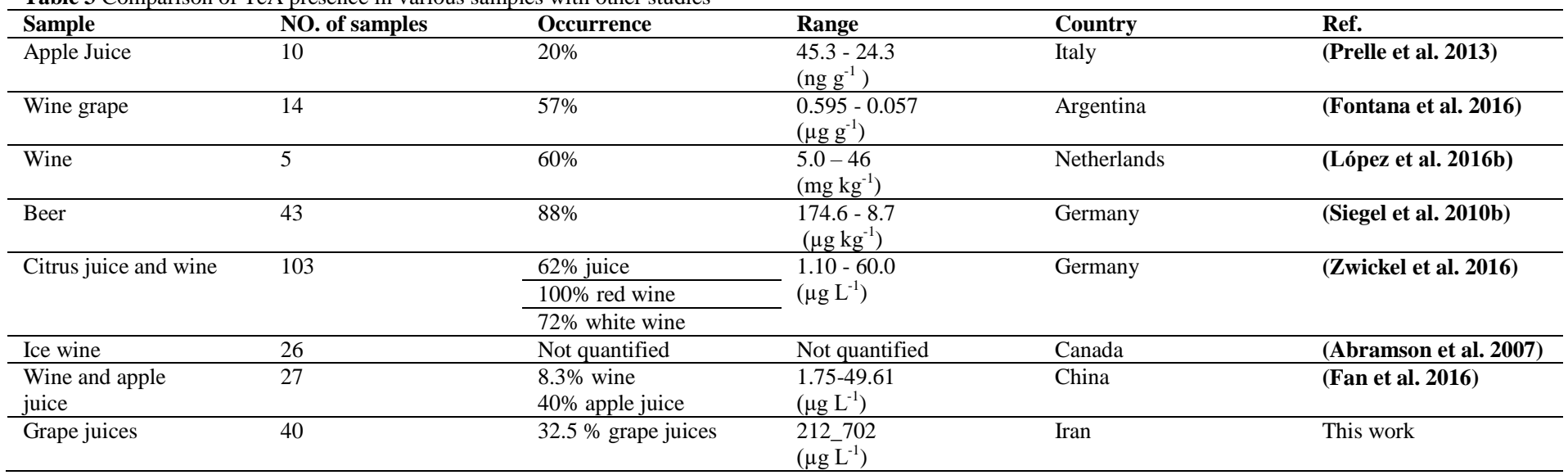

\section{CONCLUSION}

The results of this study showed HPLC-UV method could applied successfully for the quantification of the $\mathrm{TeA}$ in fruit juices. The data from this survey illustrated that TeA occurs at high levels, up to a maximum of $702 \mu \mathrm{g} / \mathrm{L}$ in grape juices. The method features a LLOQ of $10 \mu \mathrm{g} / \mathrm{L}$, good selectivity and a rapid sample preparation and analysis procedure

Acknowledgments: This is a paper of a database from the thesis entitled "Determination of TeA in some fruit juice samples using HPLC method" registered in the Tabriz University of Medical Sciences. We also gratefully acknowledge their help and financial assistance as grant.

\section{REFERENCES}

Abramson, D., Delaquis, P., \& Smith, D. (2007). Assessment of ochratoxin A and tenuazonic acid in Canadian ice-wines. Mycotoxin Res, 23(3), 147-151. doi:https://doi.org/10.1007/bf02951511

Amirkhizi, B., Arefhosseini, S. R., Ansarin, M., \& Nemati, M. (2015). Aflatoxin $\mathrm{B} 1$ in eggs and chicken livers by dispersive liquid-liquid microextraction and HPLC. Food Addit Contam Part B, 8(4), 245-249.

Asadpoor, M., Ansarin, M., \& Nemati, M. (2014). Amino acid profile as a feasible tool for determination of the authenticity of fruit juices. Adv Pharm Bull, 4(4), 359-362. doi:https://doi.org/10.5681/apb.2014.052
Asam, S., Lichtenegger, M., Muzik, K., Liu, Y., Frank, O., Hofmann, T., \& Rychlik, M. (2013). Development of analytical methods for the determination of tenuazonic acid analogues in food commodities. Journal of Chromatography A, 1289, 27-36. doi:https://doi.org/10.1016/j.chroma.2013.03.015

Asam, S., Liu, Y., Konitzer, K., \& Rychlik, M. (2011). Development of a stable isotope dilution assay for tenuazonic acid. J Agric Food Chem, 59(7), 2980-2987. doi:https://doi.org/10.1021/jf104270e

Broggi, L., Reynoso, C., Resnik, S., Martinez, F., Drunday, V., \& Bernal, Á. R. (2013). Occurrence of alternariol and alternariol monomethyl ether in beverages from the Entre Rios Province market, Argentina. Mycotoxin Res, 29(1), 17-22. doi:https://doi.org/10.1007/s12550-012-0147-6

Chen, S., \& Qiang, S. (2017). Recent advances in tenuazonic acid as a potential herbicide. Pesticide Biochemistry and Physiology, 143, 252-257. doi:https://doi.org/10.1016/j.pestbp.2017.01.003

Cheraghali, A., Yazdanpanah, H., Doraki, N., Abouhossain, G., Hassibi, M., AliAbadi, S., . . . Fallah, N. (2007). Incidence of aflatoxins in Iran pistachio nuts. Food and Chemical Toxicology, 45(5), 812-816 doi:https://doi.org/10.1016/j.fct.2006.10.026

Cheraghali, A. M., Mohammadi, H. R., Amirahmadi, M., Yazdanpanah, H., Abouhossain, G., Zamanian, F., . . A Afshar, M. (2005). Incidence of patulin contamination in apple juice produced in Iran. Food Control, 16(2), 165-167. doi:https://doi.org/10.1016/j.foodcont.2004.01.006 
Cunha, S. C., Sá, S. V., \& Fernandes, J. O. (2018). Multiple mycotoxin analysis in nut products: Occurrence and risk characterization. Food and Chemical Toxicology, 114, 260-269. doi:https://doi.org/10.1016/j.fct.2018.02.039 da Cruz Cabral, L., Terminiello, L., Pinto, V. F., Nielsen, K. F., \& Patriarca, A. (2016). Natural occurrence of mycotoxins and toxigenic capacity of Alternaria strains from mouldy peppers. Int $\mathrm{J}$ Food Microbiol, 236, 155-160 doi:https://doi.org/10.1016/j.ijfoodmicro.2016.08.005

da Motta, S., \& Valente Soares, L. M. (2000). Simultaneous determination of tenuazonic and cyclopiazonic acids in tomato products. Food Chemistry, 71(1), 111-116. doi:https://doi.org/10.1016/S0308-8146(00)00040-6

De Berardis, S., De Paola, E. L., Montevecchi, G., Garbini, D., Masino, F., Antonelli, A., \& Melucci, D. (2018). Determination of four Alternaria alternata mycotoxins by QuEChERS approach coupled with liquid chromatographytandem mass spectrometry in tomato-based and fruit-based products. Food $\begin{array}{lll}\text { Research International, 677-685. } & \text { 106, }\end{array}$ doi:https://doi.org/10.1016/j.foodres.2018.01.032

Dini, A., Khazaeli, P., Roohbakhsh, A., Madadlou, A., Pourenamdari, M. Setoodeh, L., . . . Moradi, H. (2013). Aflatoxin contamination level in Iran's pistachio nut during years 2009-2011. Food Control, 30(2), 540-544. doi:https://doi.org/10.1016/i.foodcont.2012.08.012

Ershadi, S., \& Shayanfar, A. (2018). Are LOD and LOQ Reliable Parameters for Sensitivity Evaluation of Spectroscopic Methods? J AOAC Int. doi:https://doi.org/10.5740/jaoacint.17-0363

Fallah, A. A., Jafari, T., Fallah, A., \& Rahnama, M. (2009). Determination of aflatoxin M1 levels in Iranian white and cream cheese. Food and Chemica Toxicology, 47(8), 1872-1875. doi:https://doi.org/10.1016/j.fct.2009.04.042 Fan, C., Cao, X., Liu, M., \& Wang, W. (2016). Determination of Alternaria mycotoxins in wine and juice using ionic liquid modified countercurren chromatography as a pretreatment method followed by high-performance liquid chromatography. Journal of Chromatography A, 1436, 133-140. doi:https://doi.org/10.1016/j.chroma.2016.01.069

Fernández-Cruz, M. L., Mansilla, M. L., \& Tadeo, J. L. (2010). Mycotoxins in fruits and their processed products: Analysis, occurrence and health implications Journal of Advanced Research, 1(2), 113-122. doi:https://doi.org/10.1016/j.jare.2010.03.002

Fontana, A. R., Prendes, L. P., Morata, V. I., \& Bottini, R. (2016). High throughput modified QuEChERS method for the determination of the mycotoxin tenuazonic acid in wine grapes. Rsc Advances, 6(98), 95670-95679. doi:https://doi.org/10.1039/C6RA22990E

Hashemi, M. (2016). A survey of aflatoxin M1 in cow milk in Southern Iran. Journal of Food and Drug Analysis, 24(4), 888-893. doi:https://doi.org/10.1016/j.jfda.2016.05.002

Khorasgani, Z. N., Jalali, A., Hossieni, A., \& Gudarzi, M. (2010). Determination of patulin contamination levels in produced apple juice of Ahvaz manufactory by HPLC. Tox Lett, 196, S330-S331.

Kollipara, S., Bende, G., Agarwal, N., Varshney, B., \& Paliwal, J. (2011). International guidelines for bioanalytical method validation: a comparison and discussion on current scenario. Chromatographia, 73(3-4), 201-217. doi:https://doi.org/10.1007/s10337-010-1869-2

Liu, B., Ge, N., Peng, B., \& Pan, S. (2017). Kinetic and isotherm studies on the adsorption of tenuazonic acid from fruit juice using inactivated LAB. Journal of $\begin{array}{lll}\text { Food } \quad \text { Engineering, } & \text { 224, }\end{array}$ doi:https://doi.org/10.1016/j.jfoodeng.2017.12.027

López, P., Venema, D., de Rijk, T., de Kok, A., Scholten, J. M., Mol, H. G., \& de Nijs, M. (2016). Occurrence of Alternaria toxins in food products in The Netherlands. Food Cont, 60, 196-204.

Mazaheri, M. (2009). Determination of aflatoxins in imported rice to Iran. Food and Chemical Toxicology, 47(8), 2064-2066 doi:https://doi.org/10.1016/j.fct.2009.05.027

Müller, M. E., \& Korn, U. (2013). Alternaria mycotoxins in wheat-a 10 years survey in the Northeast of Germany. Food Control, 34(1), 191-197. doi:https://doi.org/10.1016/i.foodcont.2013.04.018

Myresiotis, C. K., Testempasis, S., Vryzas, Z., Karaoglanidis, G. S., \& Papadopoulou-Mourkidou, E. (2015). Determination of mycotoxins in pomegranate fruits and juices using a QuEChERS-based method. Food Chemistry, 182, 81-88. doi:https://doi.org/10.1016/j.foodchem.2015.02.141 Nemati, M., Mehran, M. A., Hamed, P. K., \& Masoud, A. (2010). A survey on the occurrence of aflatoxin M1 in milk samples in Ardabil, Iran. Food Control, 21(7), 1022-1024. doi:https://doi.org/10.1016/j.foodcont.2009.12.021

Oliveira, R. C., Goncalves, S. S., Oliveira, M. S., Dilkin, P., Mallmann, C. A. Freitas, R. S., . . . Correa, B. (2017). Natural occurrence of tenuazonic acid and Phoma sorghina in Brazilian sorghum grains at different maturity stages. Food Chem, 230, 491-496.

Panel on Contam in the Food Ch, E. (2011). Scientific Opinion on the risks for animal and public health related to the presence of Alternaria toxins in feed and food (Vol. 9).

Patriarca, A., Azcarate, M., Terminiello, L., \& Pinto, V. F. (2007). Mycotoxin production by Alternaria strains isolated from Argentinean wheat. Int $\mathbf{J}$ Food Microbiol, 119(3),

doi:https://doi.org/10.1016/j.ijfoodmicro.2007.07.055
Pizzutti, I. R., de Kok, A., Scholten, J., Righi, L. W., Cardoso, C. D., Rohers, G. N., \& da Silva, R. C. (2014). Development, optimization and validation of a multimethod for the determination of 36 mycotoxins in wines by liquid chromatography-tandem mass spectrometry. Talanta, 129, 352-363.

Prelle, A., Spadaro, D., Garibaldi, A., \& Gullino, M. L. (2013). A new method for detection of five alternaria toxins in food matrices based on LC-APCI-MS Food Chemistry, 140(1-2)

$161-167$

doi:https://doi.org/10.1016/j.foodchem.2012.12.065

Prendes, L. P., Merín, M. G., Fontana, A. R., Bottini, R. A., Ramirez, M. L., \& de Ambrosini, V. I. M. (2018). Isolation, identification and selection of antagonistic yeast against Alternaria alternata infection and tenuazonic acid production in wine grapes from Argentina. Int $\mathrm{J}$ Food Microbiol, 266, 14-20. doi:https://doi.org/10.1016/j.ijfoodmicro.2017.10.033

Rahimi, E., Bonyadian, M., Rafei, M., \& Kazemeini, H. (2010). Occurrence of aflatoxin M1 in raw milk of five dairy species in Ahvaz, Iran. Food and Chemica Toxicology, 48(1), 129-131. doi:https://doi.org/10.1016/j.fct.2009.09.028

Rychlik, M., Lepper, H., Weidner, C., \& Asam, S. (2016). Risk evaluation of the Alternaria mycotoxin tenuazonic acid in foods for adults and infants and subsequent risk management. Food Control, 68, 181-185. doi:https://doi.org/10.1016/i.foodcont.2016.03.035

Sani, A. M., Nikpooyan, H., \& Moshiri, R. (2010). Aflatoxin M1 contamination and antibiotic residue in milk in Khorasan province, Iran. Food and Chemical Toxicology, 48(8-9), 2130-2132. doi:https://doi.org/10.1016/j.fct.2010.05.015 Siciliano, I., Franco Ortega, S., Gilardi, G., Bosio, P., Garibaldi, A., \& Gullino, M. L. (2018). Molecular phylogeny and characterization of secondary metabolite profile of plant pathogenic Alternaria species isolated from basil. Food Microbiology, 73, 264-274. doi:https://doi.org/10.1016/i.fm.2018.02.001

Siegel, D., Merkel, S., Koch, M., \& Nehls, I. (2010). Quantification of the Alternaria mycotoxin tenuazonic acid in beer. Food Chem, 120(3), 902-906.

Siegel, D., Rasenko, T., Koch, M., \& Nehls, I. (2009). Determination of the Alternaria mycotoxin tenuazonic acid in cereals by high-performance liquid chromatography-electrospray ionization ion-trap multistage mass spectrometry after derivatization with 2, 4-dinitrophenylhydrazine. Journal of Chromatography A, 1216(21), 4582-4588. doi:https://doi.org/10.1016/j.chroma.2009.03.063

Tralamazza, S., Piacentini, K., Iwase, C., \& Rocha, L. (2018). Toxigenic Alternaria species: impact in cereals worldwide. Current Opinion in Food Science. doi:https://doi.org/10.1016/j.cofs.2018.05.002

Walravens, J., Mikula, H., Rychlik, M., Asam, S., Ediage, E. N., Di Mavungu, J. D., . . . De Saeger, S. (2014). Development and validation of an ultra-highperformance liquid chromatography tandem mass spectrometric method for the simultaneous determination of free a d conjugated Alternaria toxins in cerealbased foodstuffs. Journal of Chromatography A, 1372, 91-101.

Wei, D., Wang, Y., Jiang, D., Feng, X., Li, J., \& Wang, M. (2017). Survey of Alternaria Toxins and Other Mycotoxins in Dried Fruits in China. Toxins,n 9(7), 200. doi:https://doi.org/10.3390/toxins9070200

Zhao, K., Shao, B., Yang, D., \& Li, F. (2014). Natural occurrence of four Alternaria mycotoxins in tomato-and citrus-based foods in China. J Agric Food Chem, 63(1), 343-348. doi:https://doi.org/10.1021/jf5052738

Zwickel, T., Klaffke, H., Richards, K., \& Rychlik, M. (2016). Development of a high performance liquid chromatography tandem mass spectrometry based analysis for the simultaneous quantification of various Alternaria toxins in wine, vegetable juices and fruit juices. Journal of Chromatography A, 1455, 74-85 doi:https://doi.org/10.1016/j.chroma.2016.04.066 